\title{
SIX VISIONS FOR THE FUTURE OF PERSONALITY PSYCHOLOGY
}

\author{
Verónica Benet-Martínez, M. Brent Donnellan, William Fleeson, R. Chris Fraley, Samuel D. \\ Gosling, Laura A. King, Richard W. Robins, and David C. Funder
}

\begin{abstract}
Social scientists should never try to predict the future; they have enough trouble predicting the past.

-James Q. Wilson (quoted in

Pinker, 2011, p. 118)
\end{abstract}

\section{David C. Funder}

This is an exciting time to be a personality psychologist. A few years ago a distinguished colleague described the field as "coming out of a tailspin." He was right, but things are much better now. Personality psychology's important contributions are having an increasing impact as creative researchers push forward with programs on topics as diverse as the molecular biology of genetics and the psychological dynamics of people who have been socialized in more than one culture.

Personality is the most important topic in psychology because it is where all the other areas come together. Cognitive psychology describes how people think and perceive. Developmental psychology traces the course of a person's psychological construction and change from infancy throughout life. Biological psychology explains the underpinnings of behavior in anatomy, physiology, genetics, and evolutionary history. And social psychology concerns how people respond to and affect the behavior of others. All of these subdisciplines serve personality psychology, the only field with the self-assigned mission of explaining whole people. It does this by focusing on individual differences, for the most part, but this is only natural. People are different from each other, and an understanding of how and why they differ necessarily entails a complementary understanding of the ways in which they are the same.

So it is a bit surprising, in retrospect, what a difficult time personality has sometimes had in gaining the attention and even respect of the rest of psychology, not to mention the world at large. I can identify at least three historic reasons for this difficulty. First, personality psychology has long been identified in the minds of many people with the first (and perhaps only) course in the subject that they took in college. Too often, this was (and sometimes still is) the classic "tour of the graveyard" that focuses on brilliant but long-deceased theorists and leads students to end the semester thinking the burning concern of the field is the disagreement between Freud and Jung (see Laura King's contribution later in this chapter). I actually defend the inclusion of Freud and Jung in modern personality courses, in measured doses, but a course that is restricted to theorists like these is an unforgivable misrepresentation of the field, a failure in one's duty to educate students, and a slap in the face to every contemporary personality researcher.

A second source of personality's difficulty is, of course, Mischel's (1968) critique and the ensuing decades of arguments, rebuttals, and obfuscations. The controversy resulted in some hard-won enlightenment (Kenrick \& Funder, 1988) but also left behind damage that included decimated or disestablished graduate programs, careers that ended prematurely or never even began, and a lingering image in the minds of a surprising number of smart psychologists outside the field that "personality" is a quaint, 
outdated idea that exaggerates the role of individual differences. The phrase fundamental attribution error causes personality psychologists to cringe whenever they hear it, for good reason. It serves to entrench the mistaken idea that to see personality as important is to be victimized by some kind of cognitive shortcoming. ${ }^{1}$

The third source of difficulty for personality is more self-inflicted, as communities of researchers focus on topics of great interest to themselves but of less concern to anyone else. It is interesting to debate about whether the Big Five are really Six or Seven, for example, but does anyone other than a certain kind of personality psychologist really care? I hasten to add that the question of trait structure is in fact important and even foundational for a good deal of work that does have broader relevance (and is touched on by several authors in this volume), such as (for example) predicting health outcomes or occupational success. To the extent that researchers spend their limited time and resources on a topic like this for its own sake, rather than because of its implications for larger issues, they are limiting the reach and relevance of their field-and should not be too surprised if, when it comes time to hand out grants or faculty positions, they find themselves and their colleagues pushed toward the bottom of the list.

So as we look ahead to the future of personality psychology, we need to be cognizant of both the positive and negative lessons of the past. I recently attended a lecture during which the speaker said that the secret of good health is simple: "Do the things that are good for you, and stop doing the things that are bad for you!" The health of personality psychology, as a discipline, similarly will be enhanced by following this excellent advice.

The specifics are fleshed out in the six contributions that constitute the heart of this chapter. A distinguished group of personality psychologists, all at (or still approaching) the height of their careers, were asked to envision the future of the field. As you will see, each proffers advice about what to do as well as what to avoid. The contributions were written entirely independently and have been edited only minimally, so it is interesting and instructive to notice the common themes that emerge across them, along with an almost total lack of substantive disagreement. To a surprising degree, what you are about to read is a consensus view of the future of personality psychology.

\section{ISSUES, METHODS, AND TRAINING}

\section{R. Chris Fraley}

I suspect that many of the areas of concern and interest that have characterized personality psychology over the past few decades will continue to be of interest in 30 years. Simply put, many of the questions that we concern ourselves with as a field are timeless questions (e.g., What is the structure of individual differences? How does identity develop? How do basic biological and sociological factors constrain our development?). I refer to these as timeless questions because (a) they are the kinds of questions that have been at the forefront of discourse about the human condition for millennia and (b) they are the kind of questions that cannot be answered definitively simply because our ability to address them is limited by our methods-methods that improve over time as technology evolves, as our conceptual models are refined, and as our data sources become more extensive. Undoubtedly some new content areas will emerge in 20-30 years, but I suspect the core questions motivating personality science will be the same as those that motivate students of personality today.

\section{Future Areas of Concern or Interest to Personality Psychologists}

If we take today's topic areas and extrapolate from there, I think we will see at least four broad research topics in 30 years:

Personality development. There is still a lot to be learned about the ways in which basic personality processes are assembled and unfold over time (see Caspi, Roberts, \& Shiner, 2005). In my opinion, the main limiting factor in the study of personality development at the moment is not theory but rather

${ }^{1}$ We would have all been so much better off if the original term correspondence bias had been maintained (Jones, 1990). 
the acquisition of data that are able to capture fully the way in which lives are lived, experienced, and change over time.

\section{Personality dynamics and within-person pro-}

cesses. One of the things I have found fascinating is that, in my brief time in the field to date, personality psychology has gone from a field characterized largely by between-persons analyses of individual differences to a field that has made serious and progressive steps toward studying within-person processes. These advances were due in large part to the efforts of scholars to collect intensive multiwave data within persons (e.g., Fleeson, 2001), along with the development of analytic techniques that were designed to better separate within-person effects from between-person effects (e.g., Nezlek, 2007). I hope that in 30 years it will be routine, if not trivial, for researchers to examine within- and betweenpersons sources of variation in tandem in their attempts to understand personality organization and dynamics, and for graduate departments in the future to routinely teach the analytic tools necessary to study such complex processes.

Microlevel studies of personality. Personality psychologists have had a long-standing interest in understanding the physiological processes underlying personality traits. In recent years, DeYoung, Gray, and Canli (just to name a few) have taken some valuable steps toward building conceptual models of how neurological systems might underlie individual differences in personality traits. Moreover, although the work is still in its infancy, research at the interface of molecular genetics and personality is likely to become more prominent over the years. My impression is that scholars currently are struggling to make sense of the data in this burgeoning area, with some scholars even feeling a bit demoralized. But I think the basic issues are important, and I suspect this is one of the areas in which we will see some novel insights and breakthroughs over the next 30 years.

Macrolevel studies of personality. As I highlight again later, the field currently is positioned to become an interdisciplinary leader. Scholars interested in levels of analysis beyond the individual (e.g., economists, sociologists, political scientists, epidemiologists) are starting to think seriously about individual differences and how they might influence the behavior of collective systems (e.g., Almlund, Duckworth, Heckman, \& Kautz, 2011). I believe one of the growing points of the field in the next few decades will be its integration with ideas from other social science disciplines.

Having commented briefly on content-related issues, I would like to say a few ideological words about concerns that I hope will be of interest to personality psychologists over the next 30 years.

The first thing I would like to address is what I call the relevance problem. Although all fields of psychology struggle with their own relevance to the broader society, personality psychology could put more effort into public relations. One of the things I hope personality psychologists will be concerned with in 30 years is positioning our field better in the broader political and intellectual landscape. Some of the most challenging questions a person can ask about a discipline in the humanities and social sciences are, What is the value of this? How does it improve my life? How does this help us to understand the human condition?

One of the things I appreciate about our field is that has inherent value; it is concerned with the same kinds of issues that have captured the attention of novelists, playwrights, philosophers, and everyday people for centuries. Moreover, although personality research has been valuable in advancing scientific debates, it also has revealed a lot about the kinds of concerns that shape the way we live our lives. For example, we know that personality processes predict voting behavior (e.g., Caprara, Vecchione, Barbaranelli, \& Fraley, 2007). In fact, basic personality traits predict voting behavior better than the traditional kinds of demographic variables on which the media focus (Barbaranelli, Caprara, Vecchione, \& Fraley, 2007). Individual differences in personality traits predict education attainment, physical health, and longevity (Roberts, Kuncel, Shiner, Caspi, \& Goldberg, 2007). Motivational factors predict performance on intelligence tests (Duckworth, Quinn, Lynam, Loeber, \& StouthamerLoeber, 2011). Personality traits predict job satisfaction (Judge, Heller, \& Klinger, 2008). Personality 
processes affect who we find attractive, with whom we fall in love, how those relationships function, and whether they will endure or end in divorce (Mikulincer \& Shaver, 2007).

Having said that, I do not think it is easy to explain to nonpsychologists (or even to psychologists in other subareas) why personality science is valuable. In fact, although some of my research on attachment in close relationships would seem, at least on the surface, to be intrinsically interesting to people, I still struggle to explain my work in ways that do not seem overly technical or in ways that do not seem like an arcane footnote in a larger story about the life, the universe, and everything.

Thus, I believe-or hope-that one of the major areas of concern over the next 20-30 years will be finding ways to highlight and publicize the relevance of personality science. In some ways the discipline of personality reflects an ideal merger of timeless philosophical questions and real-life, practical concerns. I hope we can find ways to leverage this strength to make our science more vital and to make its relevance more self-evident.

A second issue that I hope will be of concern to personality psychologists over the next 30 years is what I refer to as the insularity problem (see also Cervone \& Mischel, 2002). Many personality psychologists, perhaps in an attempt to justify the importance of their field, have placed some rather curious and inflexible borders around the discipline. If one is assessing and studying the Big Five personality traits, for example, one might be said to be doing "legitimate" personality science. But if one is studying the structure of individual differences in attachment orientations; trying to understand how those individual difference develop; how they are realized though various affective, cognitive, motivational, and neurological bases; and studying their implications for relationship functioning, how people cope with trauma, and so forth, then one runs the risk of doing work that some personality psychologists would argue falls outside the domain of personality science proper. Even worse, sometimes scholars will attempt to explain away such work with constructs and measures that they feel are more properly suited to capturing personality (i.e., the Big Five). And so threats to personality exist both inside and outside its own ranks.
For the field of personality to flourish over the next few decades, it needs to embrace the study of individual differences and personality processes more generally. Erecting barriers and hastily classifying some constructs as "irrelevant" to personality is likely to promote a kind of insularity that will have short-term benefits (e.g., creating solidarity among members of the in-group), but that will stunt the field's growth and its relevance in the long term. My sense is that we already have begun to outsourceunwittingly-some of the interesting questions to other disciplines. Developmental psychologists, for example, are more likely than contemporary personality psychologists to address fundamental questions, such as "Why are some people more likely to be socially and emotionally well adjusted than others?" Why? Partly because the prevailing zeitgeist in personality psychology holds that personality traits are not "developmental" constructs. (Indeed, they often are treated as exogenous variables in theoretical models rather than endogenous ones.) My colleague Brent Roberts has taken great strides to reverse this mind-set (e.g., Roberts, Walton, \& Viechtbauer, 2006), but many of his efforts have fallen on deaf ears. Consider another example: The study of individual differences in the attitudes people hold about affectively charged topics has been outsourced to social psychologists. Social psychologists, of course, always have been interested in attitudes. But attitudes once were studied commonly by personality psychologists too. If one were to try to understand the structure, development, and implications of individual differences in political attitudes these days, one would be best served by referring to texts in social psychology or political science rather than personality psychology. I suppose some psychologists might read that last sentence and say, "That's the way it should be." And perhaps they are right. But my sense is that the future of our field is not too bright if other disciplines can so easily dominate the study of individual differences in constructs that are so fundamental for making sense of human behavior and experience.

To summarize, one of the potential strengths of the field is its relevance to all areas of psychological science. Indeed, the fundamental questions of the field cut across clinical, social, developmental, 
evolutionary, biological, and other branches of psychology. In 30 years, I would like to see personality psychology as a unifying force for all of psychologya force that organizes the broader discipline. This can happen only if personality psychologists are militantly inclusive in their purview of the field.

\section{Future Methodological Innovations}

I think it is fair to claim that many of the major forces that have driven scientific and social change over the past century have been technological in nature. In fact, one of the most important technological advances in psychology has been the development of the personal computer. Psychologists have been able to use computers in their labs to precisely control the presentation of stimuli, to collect data, and to perform highly sophisticated data analyses and simulations. As of this writing, I can perform a factor analysis on my mobile phone in a matter of seconds. In contrast, when I was an undergraduate, performing such an analysis required walking to a separate building (uphill in the snow) that housed specialized (and large, high-maintenance) computers and begging an expert (who, incidentally, was also large and high-maintenance) to key in the information of interest.

The increased power and use of computers, of course, has had an unexpected, and undesirable, consequence. Namely, there is a sense in which many of us have become glued to our computers. Indeed, many researchers implicitly believe that if you cannot bring people into your lab, you cannot study them properly. The result is that our field has a lot of say about button pressing and self-reports in the laboratory (Baumeister, Vohs, \& Funder, 2007) but relatively little to say about personality processes as they play out in people's everyday lives.

This kind of complaint is not new, of course (see Carlson, 1971). But, ironically perhaps, the same kinds of technological developments that have led us down this narrow path might be poised to liberate us. Specifically, some of the most important technological developments in the past two decades have been in the area of mobile communications. The popularization of the Internet has allowed people to communicate with one another more easily and more broadly than ever. Importantly, mobile devices and smartphones have enabled people to carry this kind of connectivity with them wherever they go.

One of my hopes is that personality psychologists will leverage these advances to improve the way in which we study personality. One way in which this might be done is by studying people more intensively, yet less invasively, in their natural environments. A good example of this comes from the research of Mehl and his colleagues on the use of the Electronically Activated Recorder (EAR)—a sampling tool for tracking people's lives acoustically (Mehl, Pennebaker, Crow, Dabbs, \& Price, 2001). In short, the EAR is a digital voice recorder that people carry with them. At random or quasi-random moments during the day, the device activates and unobtrusively records a sample of audio that can be studied later by psychologists. Although the EAR is a fantastic device (and is available to everyone as an iPhone application), I suspect we will look back on it in a few decades and consider it rather clunkymuch in the same way that the cutting-edge Palm pilot and beeper studies of more than a decade ago seem dinosaur-like now. The point, however, is that the groundwork for this kind of naturalistic research has been laid and, with the exponential rate at which mobile technology improves, I believe we will see a lot more research on naturalistic personenvironment interactions in 30 years.

\section{Implications for the Training and Preparation of Future Personality Psychologists}

If I am correct in assuming that technology (and mobile technology in particular) will be one of the major driving forces affecting how personality psychologists do their work in 30 years, then it follows that a strong training program must embrace technology. What I mean by that is that it is not adequate to offer courses on the history of the field or advanced seminars in which students read and discuss classic and cutting-edge papers. Instead, competitive programs must provide opportunities for students to learn how to develop and use emerging technologies. At the University of Illinois, for example, we currently have a graduate-level course in which students learn how to create web servers, 
program interactive online surveys and experiments, and incorporate those elements into social networking platforms. I am hoping we can expand on that structure in the next few years to include in-depth training on application development for mobile devices.

An important thing to keep in mind, however, is that technological advances in microcomputing and mobile communication are increasing in an exponential fashion. That has implications not only for the training of future generations of personality psychologists but also for those who already have been trained. Namely, the relevance of our skill sets will expire quickly if we are not engaged continuously in learning. It is no coincidence that what I have learned about Internet technologies over the past 5 years I have learned from people who are younger than myself. A competitive training program in personality psychology must have a mixture of younger and older faculty — or at least faculty who are committed to the idea that education does not end once one's formal training is complete.

\section{EXPANDING THE RELEVANCE OF PERSONALITY PSYCHOLOGY}

\section{Laura A. King}

What will personality psychology look like in 20 or 30 years? I have struggled with this question in a variety of ways. I returned to 20 years ago, when I had just earned my doctorate and asked myself what I would have thought the field would look like now. I looked to the journals from 20 years before that for clues that might have predicted the status of personality in the early 1990s. I asked current graduate students in personality psychology what they imagined themselves working on in 20 or 30 years. I considered my experiences as editor of two personality journals over the past several years. All of this thinking, talking, and no small amount of mental anguish has produced the answer "I hope I have no idea." The rest of this essay will attempt to make sense of that answer. To begin, I present a brief refresher on the definition of our field and argue that optimally personality science will find its finest inspiration in the person and his or her life.
Psychology is the science of behavior. Personality psychology is that branch of psychology that examines those aspects of the person that predict his or her behavior, "the dynamic organization within the person, of those psychophysical systems that determine his (or her) unique adjustment to the environment" (Allport, 1937, p. 48). Thus, scientists who study personality have the opportunity to explore one of the most fascinating and complex topics in psychology, those characteristics, within the person, that contribute to behavior, to success, to love, to relationships, to adjustment.

Personality psychology is not the science of personality psychologists and their constructs and scales. The science of personality is not, by definition, a science of metaphors. Yet, at times, it seems we live in an academic world in which metaphors, or constructs, take on a life their own, and we begin to forget what they were invented for. Laboratory manipulations become topics of interest, per se, as if they are the phenomena of interest to our science, rather than analogues that represent a real phenomenon in the world. Excellent measurement is vitally important to the science of personality as are valid laboratory manipulations. However, in debating the factor structure of this or that scale, or the validity of this or that measure, or the meaning of responses to a particular manipulation, we lose track of the fact that even the exact right answer to these questions may leave us knowing, still, precious little about human beings or human behavior. As an editor, I have found myself (quietly) railing against a science of constructs, scales, and manipulations. The mission of the science of personality cannot be met through a conversation about topics that were invented by and that are primarily of interest to psychologists.

The scientist need not construct and invent when raw phenomena-fascinating, complex, and mysterious - are all around us demanding that we notice them and bring a scientist's sensibility to bear in explaining their nature. Consider Isaac Newton's discovery of gravity. Newton did not invent gravity. He noticed it (Stukeley, 1752). Doubtless, all of humanity had seen things falling down since there were humans to see, but it was Newton who attended to the phenomenon before him and asked 
the question "why?" Isn't this what science is about: Noticing things that happen and asking why, inspired by phenomena in the world? Personality science always will be at its most relevant and most exciting when it draws inspiration from human beings and their behavior (rather than from scholarly articles, constructs, scales, and manipulations).

If personality psychology looks to phenomena in the world for inspiration, then what personality psychology will look like in 30 years will depend on what the world includes. To the extent that personality psychology draws its inspiration from actual people and their everyday lives, its content will depend on whatever it is that human beings are doing. Certainly, in 1991, no one in would have guessed that personality psychologists would be asked to explain and understand the role of Facebook in human life. Not only the topics we study but also our methods have been changed, dramatically, by advances in the larger world. The notion that samples of thousands, available through the Internet, would replace hundreds of introductory psychology students in large-scale studies was unimaginable in 1991. In the 1990s, daily diary assessment, using pagers, was cutting edge. Twenty years later, these assessments have given way to electronic diaries using smartphones and statistical tools for detecting the reliable associations in the data they produce. Stepping out of a time machine today, my newly degreed self would be amazed and perhaps a bit frightened, like Tarzan in a modern city, sniffing the air and wondering what happened to all the paper and all the data entry.

I hope I have no idea what personality psychology will look like in 30 years. I hope that it is shockingly different from what we see today because it is ever tethered to a larger and rapidly changing world. I hope that amid debates about scales, constructs, and manipulations, personality psychologists will continue to seek to answer the question "Why?" for behaviors and phenomena that we cannot even begin to imagine today.

Perhaps these thoughts are facile or disingenuous. Even if future personality psychologists are studying, say, humans rocketing off to Mars, will we still be giving them the Revised NEO Personality Inventory to complete before they leave? Against my better judgment, then, I offer a few thoughts on trends that I believe may be emerging in the field, beginning with a brief perusal of rejected papers.

As an editor, I read many papers that contain provocative ideas but lack empirical evidence commensurate with those ideas. Such papers give a sense of the ideas that are bubbling just below the surface of our published literature. To me, some of the most interesting of these ideas have to do with recognizing, in varying ways, that persons are in bodies and that personality shapes and is shaped by that physical reality. One might argue that personality psychology has been characterized by a kind of implicit dualism. At times, personality seems to occupy a place of near mysticism-a thing like the soul or the mind-that exists separate from the body and its actions. Something like the person-situation debate could happen only in a context in which this unspoken dualism existed. Our bodies exist and emit behaviors. Those behaviors have an undeniable coherence that emerges, as it must, around the body that emits them. Social perceivers (and personality psychologists) need personality to explain the coherence of behavior not because social perceivers (and personality psychologists) are not rational or are prone to attributional errors but rather because those behaviors come from the same body, the same embodied person. The body, then, might be thought of as the organizing principle of personality. Greater attention to the physicality of the person, and all that that implies, is an important future direction in personality science, and one that surely will come to fruition as the methods of neuroscience become more amenable to the logistics of research on individual differences.

In addition to taking the body more seriously, I predict that personality psychology in the future will reap unexpected benefits from the current dominant trait approach, the Five-Factor Model (FFM) or Big Five. In my view, two important and perhaps unexpected trends bear mention as they portend good things in the future. First, I would suggest that rather than remaining preoccupied with the specific five factors, we are seeing a greater amount of empirical attention paid to higher order and, perhaps more important, lower level units of analysis. The trait domain is expanding, not only upward but 
back down to more circumscribed individual differences (see Chapter 11, this volume). Lower level facets (and more specific units of every kind) are finding their way back into the conversation about important associations between personality and consequential outcomes.

Second, the five factors have given personality psychology a sound bite. These five traits, whose number fortuitously coincides with the median capacity of human working memory, have given our colleagues in other areas of psychology a foothold into individual differences. They have provided a vocabulary for conversations that include personality and individual differences even among scholars who never have been able to see the value of such differences in the past. It may be that such conversations lead, ultimately, away from the FFM toward other models or other characteristics, but that the FFM has allowed the conversations to occur at all, is notable. These conversations are particularly important at the boundary that separates personality and social psychology.

Personality and social psychology fundamentally differ in the places we look for the causes of behavior. Social psychologists look to the context. Personality psychologists look to the person. Social psychologists typically use experimental paradigms to demonstrate the causal role of situational factors in producing behavioral differences between people. Personality psychologists, interested in those psychological qualities that people carry with them into (and out of) situations, are more likely to rely on correlational methods. It is perhaps a frustration for personality psychologists that research on individual differences is trapped in the methods and language of correlational research. Variables are correlated, predictive, or associated but very rarely causally related. Importantly, getting closer to the truth of human behavior requires the language of personality. How do situations influence behavior? Increasingly, the answer, even for social psychologists, is and will continue to be "It depends." The incorporation of individual differences as an essential part of the larger science of behavior is vital to describing human behavior with precision and ever more exacting accuracy.

To close, I cannot resist one last prediction, more a wish, perhaps, than a hope. I wish that personality psychologists would give greater attention to the way our field is presented to students in high schools and at the undergraduate level. I wish more personality psychologists would teach introductory psychology. Saving this, I wish more individuals who teach psychology to undergraduates would come to recognize that even students who have great mastery of the historical theories of personality are not well prepared for the science of personality as it exists today, nor how it will exist in 30 years. It is unacceptable that personality psychology remains, generally, a side trip through the history of psychology while the rest of the science of psychology is presented to students through the lens of the most cutting-edge research.

No one would consider introducing students to cognitive psychology without ever mentioning working memory (a far newer idea than psychoanalysis) or research incorporating brain imaging. For some reason, though, it is acceptable to leave generations of potential personality psychologists with the impression that nothing interesting has happened in our field since Carl Rogers. ${ }^{2}$ In conversations with instructors, nothing has been more horrifying than hearing that personality psychology ranks high among the topics they consider skipping in their introductory psychology courses because Freud is not interesting to students. Surely, we can debate the place of classic theories in the pedagogy of personality. But to sow interest in our field, so that we still have personality psychologists in 30 years, individuals who might be enthusiastic about the scientific exploration of the most complex and exciting aspect of human life must be given a hint that our field exists.

\section{MECHANISMS, ENVIRONMENT, INNOVATION, AND RIGOR}

\section{William Fleeson}

Two basic assumptions of the field are especially attractive to me: (a) the recognition that life events

\footnotetext{
${ }^{2}$ As Larsen and Funder noted, the authors of some personality textbooks (e.g., Funder, 2013; Larsen \& Buss, 2009) certainly have recognized this "tour of the graveyard" problem and have written texts to teach personality as a contemporary and lively area of knowledge that is broadly relevant to how we live our lives.
} 
and experiences affect who people are, which reciprocally affects what people do to their environment, throughout their life; and (b) the conviction that lifestyles, rationality, values, and beliefs (the qualities that make us most human, that we cherish the most, and that have the most impact on the world) are variables that extend and flow over time-we cannot explain such variables on the basis of current, transitory configurations of environmental variables.

\section{An Ideal Future: Content}

After a successful period of defending the existence (e.g., Epstein, 1979; Fleeson, 2001; Fleeson \& Noftle, 2009; Funder \& Colvin, 1991; Funder \& Ozer, 1983) and the importance of personality (e.g., Ozer \& Benet-Martinez, 2006; Roberts et al., 2007), the field is ready to resume working on the problems it put aside for a few decades, namely, the reciprocal impact between the environment and the person, extended over time. The field, however, has benefited greatly from controversy (Kenrick \& Funder, 1988), such that it has a new, more adequate account of personality. This new account both has a firm grasp of the descriptive dimensions of traits (Ashton \& Lee, 2007; Fleeson \& Gallagher, 2009) and also finally includes explanatory socialcognitive concepts (Mischel, 1973; Mischel \& Shoda, 1998), allowing the study of whole traits, not just parts of traits (Fleeson, 2012).

\section{The power of the environment in shaping per-} sonality. In the future, personality psychologists will effectively study the ways in which events, relationships (Sroufe, 1989), peers, work, and roles (Roberts \& Wood, 2006) shape and create personality. I believe there are at least two reasons to study the long-term, lasting influence of situations on who people are and how they act over time. First, an unfortunate side effect of the person-situation debate is that environments often are conceived of as contrary to personalities and as having only momentary, concurrent effects on behavior. Personality psychologists, in alliance with developmental psychologists, can revive the partnership of personality with environment as well as the lasting influences of momentous and recurring situations on people. Second, identification of the environmental features that do and do not matter, and of where environment gets its power, will facilitate widespread reduction of deleterious outcomes, such as mental disorder and misery, while increasing the likelihood of people reaching their full potentials. If there is hope for improving personality, then much of personality has to arise in the environment.

Mechanisms underlying traits. The future of personality will include extensive and detailed discoveries of the mechanisms constituting traits. I believe there are at least three reasons to study how traits become manifest in actual behaviors, thoughts, and emotions; the ways in which they change; of what they consist; how they lead to outcomes; and how they are formed in the first place. First, traits have been treated like black boxes, impossible to look within, yet the source of all personality behavior. But if traits are the key (or among the key) variables in personality, it will begin to be embarrassing that personality psychologists do not understand their internal workings. Second, it is essential if personality psychology is to be taken seriously as a science that it do more than describe. Detailing the mechanisms of traits will begin to move personality toward being an explanatory science. A third reason to study mechanisms is that they pinpoint locations for potential interventions to help people realize their potentials and to take advantage of the many important ways personality affects important outcomes like happiness, work success, marital satisfaction, and longevity. In fact, I believe this is so important to the future of personality psychology that I have begun working on this problem already. Whole trait theory (Fleeson, 2012) is my attempt to wed social-cognitive mechanisms to descriptive trait concepts.

Morality and ideology. The future of personality psychology will include a personality-based approach to the study of moral (ethical) behavior, and to its opposite-immoral behavior. I believe there are at least two reasons to investigate morality from a personality perspective. First, the question of what drives and determines moral behavior has occupied thinkers for thousands of years, originally 
in the field of philosophy and relatively recently in psychology and other fields, and much of morality and ethical behavior may be based on long-standing psychological characteristics that exist within individual persons and on which individuals differ. A second reason to study morality is that the practical impacts of ethical and unethical behavior in society are enormous and relevant to multiple disciplines. Education, business, criminology, economics, sociology, political science and other disciplines care deeply about the consequences of ethical behavior, the ability to evaluate character, and the means to shape it. Personality psychology may be uniquely suited to address scientifically the UNESCO motto: "Since wars begin in the minds of men, it is in the minds of men that the defenses of peace must be constructed."

Clinical disorders. In the future, personality psychology will include substantial investigation of the nature and functioning of clinical disorders. For at least three reasons, it will be important for personality psychologists to detail the psychological mechanisms underlying, to clarify the conceptual underpinnings of, to find the basic dimensions constituting, and to discover the causes producing mental disorders of all types but especially personality disorders. First, continuity between so-called normal personality and clinical disorders means that personality psychologists can study basic personality at the same time they are directly affecting the health of many suffering individuals and of the nation as a whole. A second reason for personality to devote substantial attention to the personality disorders is that clinical disorders are the psychological equivalents of centrifuges-they concentrate many of the interesting events, behaviors, and emotions of normal personality into shorter time periods, allowing more intensive study of the interesting components of personality. Finally, the National Institute of Mental Health's new requirements for direct clinical relevance create a wonderful opportunity for financial support of personality's new growth.

\section{An Ideal Future: Methodological Innovations}

Each of the following innovations would allow addressing important conceptual questions, questions that have bedeviled personality psychologists for decades. I believe massive Internet samples, such as those collected by Gosling and colleagues (e.g., Soto, John, Gosling, \& Potter, 2011; N = $1,267,218$ ) will become commonplace. This will allow for precise estimates of parameters, rapid evaluation of multiple ideas, controlling for hosts of variables, highly accurate networks of construct validity, experience sampling method studies with large Ns, and the ability to recruit large Ns of even rare individuals. Virtual reality may liberate many new types of experimental innovations, such as experiments that occur in simulated real life (Freeman et al., 2005). Measurement accuracy and precision may increase greatly to the point at which psychologists can confidently measure personality characteristics with high reliability and validity. Ideally, measurement will allow accurate assessments of unconscious variables and perhaps even allow objective assessments of "true" personality and wellbeing. Finally, innovative techniques may allow for manipulation of long-standing variables, such as personality traits, and important variables, such as life events. Although we cannot currently conceive of how this would happen, perhaps someone will invent relevant effective and ethical methods.

\section{An Ideal Future: Methodological Practices} In the future, personality psychologists will have a renewed commitment to methodological rigor. Already among the most rigorous of the psychological subfields, it nonetheless could stand to gain. This rigor would include a continued insistence on cumulative science in which findings from different labs build together (one of the biggest current positive features of personality psychology). It would include a respect for rational argumentation, an expectation of statistical expertise among its researchers, rejection of practices that inflate false findings (e.g., Simmons, Nelson, \& Simonsohn, 2011), acceptance of wise exploration of data, and honest, nonexaggerated, full-disclosure reporting of studies (which in turn would not unduly damage publication chances).

\section{An Ideal Future: Conclusion}

In an ideal future, personality researchers care deeply about methodological rigor, take advantage 
of massive samples, invent new techniques for assessment and interventions, demystify clinical disorders, explain why some people are moral and others are not, detail the mechanisms constituting traits, and identify lasting consequences of the environment. The future will include many other things, such as unpacking the Big Five and discovering how individuals can realize their potentials, but in these few pages, I could not cover them all. These advances will allow personality psychology to realize its potential to study the long-term impact of the environment on what people do; on how they affect the environment; and on their beliefs, values, and lifestyles.

\section{INNOVATIVE TOOLS AND TECHNOLOGIES FOR STUDYING PERSONALITY}

\section{Samuel D. Gosling}

In recent years, psychology in general and personality psychology in particular have been soundly criticized for an overreliance on selfreport methods (Baumeister et al., 2007; Furr, 2009), focusing on a limited set of activities (Rozin, 2001, 2006, 2009) performed by a select group of participants (Gosling, Vazire, Srivastava, $\&$ John, 2004; Henrich, Heine, \& Norenzayan, 2010). Personality researchers are examining an enormously diverse range of research questions. So if they are to make progress on these questions in the coming decades, they will need to expand their methodological repertoire considerably.

Given the past challenges of studying individuals in their daily lives, the tiny window through which researchers have been observing the diverse and complex world of personality is understandable. But, three recent developments have deprived researchers of their excuses for focusing on narrow methods, populations, and phenomena: The enormous growth of the Internet, the widespread adoption of mobile technologies, and the establishment of animal models of personality. In the coming decades, we envision that the field of personality will harness these developments to allow researchers to broaden the methods, phenomena, and populations they study.

\section{Internet Research}

Personality scientists can use the Internet to improve their research in three main ways (Johnson $\&$ Gosling, 2010). First, they can use the Internet as a particularly efficient means for delivering traditional self- and informant-report measures to participants (Johnson, 2010; Vazire 2010). The global reach of the Internet means it can be used to deliver these reports to a much larger, much broader, and harder-to-reach populations than is viable with traditional methods (Gosling, Sandy, John, \& Potter, 2010). Such studies allow researchers to provide participants with immediate feedback, automatically check for errors (e.g., missing responses), screen for invalid protocols (e.g., due to acquiescent responding), implement adaptive testing (e.g., where the response to one stimulus determines which stimulus is presented next), and present media, such as video, as part of the stimulus materials (Reis \& Gosling, 2010). In addition, the Internet has facilitated the use of efficient crowd-sourcing methods in which individuals can be paid to participate in studies (Buhrmester, Kwang, \& Gosling, 2011).

A second way personality researchers can use the Internet is to study phenomena that have long interested them but have, until now, been hard to study in real-world contexts. For example, electronic traces left by real social interactions as they play out in the contexts of email, short-message system texts, and other forms of online communication yield ecologically rich data for researchers interested in interpersonal traits like extraversion and agreeableness. Researchers interested in preferences, values, and goals can examine patterns of online media consumption and explicit statements broadcast to the world (e.g., in blog posts, tweets, etc.), perhaps making use of powerful text-analysis programs.

A third way personality researchers can harness the Internet is by examining new social phenomena that are specific to the Internet but nonetheless may provide illuminating insights into personality processes. For example, in virtual worlds and online gaming contexts, options of decorating and furnishing virtual spaces (e.g., in Second Life) are not subject to the practical, physical, and financial constraints associated with real-world spaces. The virtual world provides many more possibilities than 
those afforded by real life for experimenting with one's physical representation (e.g., choosing avatars or game characters of a different sex, race, body type, and species).

In addition to being a domain in which to construct new studies to collect data, the Internet already contains rich preexisting deposits of psychologically relevant data that vigilant researchers can harvest. For example, the millions of pages of text that are created online everyday provide an enormous source of preexisting data. One project analyzed the diaries of more than 1,000 U.S. users of an online journaling service spanning a period of 4 months, starting 2 months before the September 11 terrorist attacks (Cohn, Mehl, \& Pennebaker, 2004); in doing so, it bypassed many of the methodological obstacles of trauma research and provided a finegrained analysis of the timeline of human coping with upheaval.

\section{Mobile Sensing}

In recent decades, ambulatory-assessment methods have begun to gain some traction in personality research, and the new handbook on the topic (Mehl $\&$ Conner, 2012) is sure to spur its growth. Existing ambulatory methods tend to rely on participants carrying specialist devices or specially programmed phones. In the coming years, we envision the widespread use of the sensors found in smartphones. Already, smartphones contain sensors that can detect, among other things, location, sound, light, movement, orientation, and nearby radio frequency identification tags; computer scientists are collaborating with psychologists to harness the potential of these devices, which can collect data, processes them, and send them to researchers. In the coming decades, these sensors should play a pivotal role in weaning personality researchers from their reliance on self-reports.

In addition, smartphones increasingly are serving as the nexus for an enormously broad and growing array of activities and social interactions; these include talking, texting, e-mailing, taking photographs, and a mind-boggling variety of activities performed via mobile-phone applications; the phones also retain a record of Internet search history, location, and other user statistics. Forensic software can be used to download and save all information from mobile phones, including deleted messages, e-mails, and photographs. So even when not serving as mobile sensors, smartphones are remarkably rich repositories of traces of individuals' behaviors. Clearly, mining such information will require that a number of basic practical and ethical challenges are solved; but once these challenges have been addressed, the data should prove enormously valuable in the coming decades.

\section{Nonhuman Animal Models of Personality}

In recent years, researchers have established the conceptual and practical viability of assessing personality in nonhuman animals (Gosling, 2001, 2008). This early work has provided the foundation for three broad domains of animal-personality research (Weinstein, Capitanio, \& Gosling, 2008). First, comparative animal studies of how personality processes and personality structure vary across species can provide a starting point for understanding the proximate and ultimate causes of personality; for example, findings across species can be combined using comparative phylogenetic approaches to shed light on the timing and original function of personality traits (Eastwick, 2009; Gosling \& Graybeal, 2007). Second, animal models of personality afford researchers with levels of experimental control over environmental and genetic factors that cannot be exercised practically in human populations. These features, coupled with a greater ability to manipulate independent variables and assess dependent variables, provide powerful tools for exploring basic issues questions about the factors that underlie personality traits. Moreover, the accelerated life course of many animal species compared with humans means that longitudinal and multigenerational studies typically can be done more quickly than they can in human populations. Finally, research is set to continue on practical applications of animal personality research; studies in this domain tend to focus on the interaction between humans and animals, including the welfare of animals used in scientific experiments, animals as pets, conservation of endangered species, and improving the effectiveness of working animals (Sinn, Gosling, \& Hilliard, 2010). 


\section{Summary}

Of course, all methods have their unique pros and cons. So if the above methods are to help shape the field in the coming decades, they must do so by augmenting the current methods, not replacing them. If they do, research in the next decades will be marked by increasing levels of ecological validity that will allow researchers to understand how personality processes are played out in the real world.

\section{CULTURAL PERSONALITY PSYCHOLOGY}

\section{Veronica Benet-Martínez}

I am homo sapiens, I am American. -Rozin (2003, p. 281)

Personality is shaped by both genetic and environmental factors; among the most important of the latter are cultural influences (Benet-Martínez \& Oishi, 2008; Church, 2010). ${ }^{3}$ Culture, which is transmitted through language, media messages, cultural practices and institutions, values and artifacts, and the modeling of behavior (Cohen, 1996; Markus \& Kitayama, 1998), however, does not have a deterministic influence on individuals' behavior. Rather, its influence is probabilistic (Allport, 1961). Rohner's (1984) metaphor comparing culture to a game (with various rules) and people to its players clearly illustrates this point. Players can pick from different strategies and options, and sometimes even violate or modify the rules if they think they can get away with it. In other words, the degree to which players follow the rules differs across individuals, depending on their personalities, personal preferences, moods, and specific situations. This results in a great deal of within-culture heterogeneity and individual differences in the degree to which people endorse, internalize, and utilize particular rules or norms (see also Oishi, 2004).

Today, most personality psychologists agree that the systematic study of how culture influences intraand interpsychological processes should be an essential part of our discipline. Broadly speaking, cultural personality studies have elucidated how macrocontextual factors mediate and moderate personality outcomes (e.g., Schimmack, Radhakrishnan, Oishi, Dzokoto, \& Ahadi, 2002), helped dispel shaky cultural stereotypes (e.g., Terracciano et al., 2005), and tested the generalizability of our theories (e.g., Benet-Martínez \& John, 1998). More specifically, culture has been linked to numerous personality-relevant variables and processes (for a review, see Benet-Martínez \& Oishi, 2008).

The future of cultural personality studies is exciting. Personality researchers interested in how cultural factors influence personality-relevant processes and structures can profit from some new promising theoretical and methodological developments in the field, such as the integration of cultural and evolutionary approaches (Norenzayan \& Heine, 2005; Rozin, 2003), the growing interest in the psychology of globalization and multiculturalism (Hong, Morris, Chiu, \& Benet-Martínez, 2000), and the availability of multilevel modeling statistical techniques to compare and link findings at the individual and cultural levels (van de Vijver, van Hemert, \& Poortinga, 2008).

The need for personality psychology to respond to the theoretical and methodological questions posed by the growing phenomenon of multiculturalism cannot be overestimated. In their sampling and design choices, personality researchers (including those who do cultural work) often have assumed implicitly that culture is a stable, uniform influence and that nations and individuals are culturally homogeneous. But rapid globalization, continued massive migration, and the resulting demographic changes have resulted in social spaces (schools, homes, work settings) that are culturally diverse, and in the growing number of individuals who identify with and live in more than one culture (Benet-Martínez, 2012; Hong et al., 2000). Current and future cultural studies in personality need to move beyond traditional between-group cultural comparisons and develop theoretical models and methodologies that capture the multiplicity and

${ }^{3}$ Culture consists of shared meaning systems that provide the standards for perceiving, believing, evaluating, communicating, and acting among those who share a language, a historic period, and a geographic location (Triandis, 1996). More recently, Chiu and Hong (2007) have defined culture as a network of knowledge that is both procedural (learned sequence of responses to particular cues) and declarative (representations of people, events, and norms) and is produced, distributed, and reproduced among a collection of interconnected people. 
malleability of cultural meaning within individuals. Some recent studies have taken this approach in examining the interplay between personality dispositions and psychosocial processes such as acculturation (Ryder, Alden, \& Paulhus, 2000), multicultural attitudes (Van Der Zee, Atsma, \& Brodbeck, 2004), bicultural identity structure (Benet-Martínez \& Haritatos, 2005), and bilingualism (Chen, BenetMartínez, \& Bond, 2008; Ramírez-Esparza, Gosling, Benet-Martínez, Potter, \& Pennebaker, 2006).

Recent research on the effects of multiculturalism and multicultural experiences on the individual also shows that through exposure to and internalization of different cultures, minority and majority individuals can experience different ways of learning, viewing, and reacting to the world. This experience makes these individuals' personalities and cultural identities more complex and layered and enriches their cognitive and behavioral repertoires (Amiot, de la Sablonniere, Terry, \& Smith, 2007; Benet-Martínez \& Haritatos, 2005). These psychological processes lead to higher cognitive complexity and more creative and tolerant thinking (Benet-Martínez, Lee, \& Leu, 2006; A. Leung, Maddux, Galinsky, \& Chiu, 2008). These attributes are an indispensable skill in our global world.

Future cultural research in personality also can benefit from exciting methodological advances in the analysis of individual and cultural data (van de Vijver et al., 2008). Because cultural, social, and personality processes operating at the individual level may not replicate at the cultural level and vice versa (K. Leung \& Bond, 1989; see Benet-Martínez, 2007), researchers can use multilevel modeling and latent-class techniques to deal with these complexities (e.g., Eid \& Diener, 2001; Lucas \& Diener, 2008; Reeskens \& Wright, 2011). These still relatively underused techniques have the potential to foster a fruitful synergy between the fields of personality and social psychology—which have provided a wealth of information regarding individual- and group-level characteristics (e.g., traits and values, majority-minority status) - and the fields of anthropology and sociology, which are informative regarding culture-level phenomena (e.g., economy, religion, and many other key demographic factors).

In addition, although many studies have established that cultural forces influence social behavior and personality (i.e., culture $\rightarrow$ person effects), almost no attention has been given to the processes by which individual factors in turn influence culture (person $\rightarrow$ culture effects). Evidence from some studies shows, for instance, that our personalities shape the cultural contexts in which we live by influencing both microcultural spaces (e.g., personal spaces, music preferences, content and style of personal web pages, etc.; Gosling, Ko, Mannarelli, \& Morris, 2002; Rentfrow \& Gosling, 2003; Vazire \& Gosling, 2004) and macrocultural elements (e.g., political orientation and participation, etc.; Gallego \& Oberski, 2012; Jost, Glaser, Kruglanski, \& Sulloway, 2003). McCrae (2004) theorized that aggregate levels of certain traits may contribute to and reinforce features of cultures, such as individualism versus collectivism. In fact, personality effects (at the individual, interpersonal, or social-institutional level) are ubiquitous, influencing each of us all the time, and when aggregated to the population level such effects are routinely consequential (Ozer \& Benet-Martínez, 2006). In short, I believe that future cultural work in personality will benefit from using designs in which researchers also explore personality effects on culture.

Lastly, to the extent that social and personality psychology can be seen as two distinct (but relatively similar) "cultures" within psychology (Funder \& Fast, 2010; Tracy, Robins, \& Sherman, 2009), and that a strong body of evidence attests to the adjustment benefits of having two cultures and integrating them with oneself (for a review, see Benet-Martínez, 2012), I argue that the future of both personality and social psychology would benefit from being more blended. Although some evidence indicates that this integration exists already at the institutional level (e.g., Journal of Personality and Social Psychology, Society for Personality and Social Psychology), the blending and integration of questions, methods, and theories from the two subdisciplines is less obvious at the individual (i.e., researcher) level (Tracy et al., 2009). This is unfortunate given that, as shown with the studies linking multiculturalism and multilingualism with general cognitive benefits, the integration of social and personality psychologies could lead to personality research that is more innovative, multifaceted, and significant. 


\section{CAUSAL FORCE, PSYCHOPHYSICAL SYSTEMS, AND PLURALISM: A RETURN TO ALLPORT}

\section{Brent Donnellan and Richard A. Robins}

A common core to human social behavior cuts across nations, cultures, and historical periods. Against this backdrop of human universals, individuals differ dramatically in their characteristic thoughts, feelings, and behaviors. The mission of personality psychology is to understand the origins, development, and consequences of human individuality from the cradle to the grave. Since its founding as a scientific discipline more than a century ago, the study of personality has had a rocky history, rising and falling from prominence within the broader field of psychology. Few other subdisciplines have had to fight as hard for scientific legitimacy and sheer existence (e.g., Funder, 2001; Lucas \& Donnellan, 2009; Swann \& Seyle, 2005). Fortunately, recent advances in the understanding of the nature, structure, and development of personality have sparked a renaissance, and personality psychology is now a vibrant field with ties to clinical, developmental, health, organizational, quantitative, and social psychology as well as burgeoning connections with economics, education, epidemiology, genetics, neuroscience, public health, psychiatry, and sociology.

Inspired by this recent energy and excitement, there is a growing sense of optimism about the future of personality psychology. However, making definitive statements about the future directions of a field as diverse as personality psychology is a risky proposition. As the quotation at the opening of this chapter implies, we are well aware of the pitfalls involved in predicting the future. Nonetheless, we offer a few speculations about the future of personality psychology by drawing on insights from the past. The scientific study of personality often is traced to the writings of Gordon Allport, including his classic 1937 text. We believe that Allport's seminal ideas are still relevant today and offer a framework for thinking about the future of the field. In the following sections, we outline three future directions inspired by Allport's approach and comment briefly on how these directions may impact the training and preparation of the next generation of personality psychologists.

\section{Understanding the Causal Force of Personality}

Allport (1937) famously noted that "personality is something and does something" (p. 48). Personality psychologists have now compiled an impressive body of evidence showing that personality attributes predict some of the most consequential outcomes in a person's life-health, wealth, happiness, and mortality. Indeed, traits prospectively predict success in academic and employment settings, and the capacity to have successful and lasting romantic relationships, as well as criminality, drug abuse, psychopathology, and subjective well-being (e.g., Moffitt et al., 2011; Ozer \& Benet-Martínez, 2006; Roberts, et al. 2007). The strength of personality's predictive power compares favorably to socioeconomic status and cognitive ability (Roberts et al., 2007) as well as to many of the biomedical measures that predict diseases, such as electrocardiogram stress tests, ultrasound exams, and screening mammograms (Meyer et al., 2001).

The tangible life outcomes predicted by personality dispositions have enormous societal relevance, yet the field of personality psychology has relatively little influence over public policy (but this might be changing; see Roberts, Donnellan, \& Hill, in press). In our opinion, this reflects the impoverished understanding of the causal role of personality in affecting life outcomes. Whether the predictive power of personality reflects a causal process or some other form of association rarely is established in a convincing fashion in published articles. Personality psychologists are justifiably afraid of invoking causal language, given the stinging criticisms often administered to those who conflate correlation with causation. This fear of causal language and the general fear of drawing causal inferences from correlational designs, however, may end up diluting the impact of personality research.

David Kenny once remarked that

the career of a hypothesized causal relationship might be as follows: first, the consistent replication of a crosssectional relationship; second, the finding of time-lagged relationships between 
cause and effect; third, the finding of cross-lagged differences; and fourth, an experiment in which the causal variable is manipulated. (1975, p. 901)

From this perspective, the "career" of most personality findings has yet to mature, as most personality research progresses only to the second or third steps outlined by Kenny. The usual stumbling block for personality effects is when it comes to designing suitable experimental tests. Given the difficulty of manipulating personality, it seems plausible that most trait-outcome associations will end their causal career at the cross-lagged stage. Recent research, however, by Jackson, Hill, Payne, Roberts, and Stine-Morrow (2012) has suggested that targeted interventions can modify even presumably basic traits such as openness to experience. Thus, it might be possible to modify personality traits either through educational training, pharmacology, or psychological interventions.

It is also worth questioning whether experimental evidence is always a necessary threshold that must be passed before invoking causal language for describing personality-outcome associations. An emerging literature is working to establish the conditions under which causal processes can be inferred from nonexperimental designs (for a review, see Foster, 2010). In fields as diverse as developmental psychology, economics, and epidemiology, it has become increasingly common to draw causal inferences from nonexperimental data, using techniques such as propensity score matching (Rosenbaum \& Rubin, 1983) and econometric approaches (e.g., Heckman, 2008). We expect that personality psychology will play an important role in prompting psychologists of all persuasions to adopt a more sophisticated understanding of generalized causal inference. In fact, personality researchers should be at the forefront of this movement given their familiarity with nonexperimental methods. Moving toward a greater appreciation and understanding of causal inference likely means that the training of future personality psychologists will involve additional course work on causal inference and advanced quantitative methods such as techniques for analyzing longitudinal, panel, and time-series data.
In further service of an improved understanding of causal relations involving personality traits and life outcomes, we predict that the future will hold a greater rapprochement between those personality psychologists more strongly identified with trait perspectives and those more strongly identified with social-cognitive perspectives (Lucas \& Donnellan, 2009; Roberts, 2009). The merging of these two traditions will help researchers articulate and investigate the proximal mechanisms by which broad dispositions actually influence consequential life outcomes. It is all too common to read an article or attend a talk in which a well-intended personality trait researcher invokes the need for future research to clarify mediating processes. This promissory note rarely is fulfilled. Hopefully, personality trait researchers will begin to pay more attention to the kinds of process variables that characterize social cognitive approaches to personality. It is quite likely that an important sequence in the causal chain linking broad dispositions to specific life outcomes involves social-cognitive mediators. For example, attribution processes and perceptual tendencies (or biases) are plausible mechanisms by which a disposition like neuroticism is associated with relationship dissatisfaction (Dyrenforth, Kashy, Donnellan, \& Lucas, 2010; Robins, Caspi, $\&$ Moffitt, 2000). We expect that more sophisticated process-based causal explanations will characterize the study of personality-life outcome associations in the future.

\section{Understanding the Psychophysical Systems Associated With Personality Variability}

Allport took a realist perspective on traits and defined personality dispositions as causal entities that were instantiated in "psychophysical systems." This interest in the biological correlates of human individuality has long been a part of the discipline of personality psychology. As a consequence, the kinds of destructive and polarizing debates involving nature versus nurture that characterize other branches of psychology like developmental psychology have not fomented in personality psychology. Allport (1937) himself noted that "no feature of personality is devoid of hereditary influences" (p. 105). This kind 
of openness means that personality psychology is well positioned to play a key role in understanding the interplay between biology and psychology. Indeed, every indication suggests that interest in this topic will persist and even increase over the next 20 or 30 years.

It is probably safe to assume that Allport could not have envisioned the advances in neuroimaging and genetic analysis that have come to the forefront of psychological science in the last 10-20 years. These technological advances have provided researchers with an impressive and powerful set of tools for understanding the biological bases of human individuality. Intriguing preliminary evidence now is linking core personality dispositions, such as the traits captured under the Big Five domains, to neurological systems and structures (e.g., Canli, 2008; DeYoung et al., 2010). These kinds of advances ultimately will fill in the "black box" element of Allport's insights about the biological bases of personality. On the other hand, we would be remiss if we did not acknowledge that research into the biological bases of personality is a challenging enterprise that even may become demoralizing at times. For example, wariness is growing about the prospect of substantial effect sizes attached to any single genetic factor (such as a single-nucleotide polymorphism) when it comes to explaining personality variability (de Moor et al., 2012). Understanding the biology of personality is not going to be particularly easy, straightforward, or uncontroversial (see Chapter 3, this volume). Nonetheless, the quest to clarify the biology of personality attributes will characterize the field for the foreseeable future. This means that the training of future personality psychologists will need to emphasize neurobiology and genetics along with the traditional psychological coursework that characterizes current training requirements. It is also safe to assume that a complete and comprehensive understanding of the biology of personality will involve largescale collaborations and massive multimethod efforts to collect wide and deep data sets. Thus, personality researchers will need to learn to work productively with scientists from a range of disciplines on large projects.

\section{Affirming Allport's Faith in Pluralism and Fulfilling His Quest to Understand the Whole Person}

Gordon Allport was an intellectual luminary with diverse interests. He was open to using a number of methodological and conceptual tools and offered the maxim that "No doors should be closed in the study of personality" (1946, pp. 133-134). Allport refused to allow an overarching theoretical orientation to obscure his mission to understand the whole person and all facets of individuality. We predict this spirit will continue to characterize personality psychology in the foreseeable future. The field adopts a "by any means necessary" approach and this orientation is one reason why personality psychology is well suited to addressing big questions about human nature.

In line with these observations, we expect that personality psychology will continue its tradition of methodological rigor and innovation. Questions about the nature of individual differences are investigated at multiple levels of analysis, from genes to sociocultural contexts. Consequently, personality researchers use a broad array of methods ranging from self-report questionnaires, reaction time tasks, behavioral measures, experience sampling responses, brain imaging, and genetic testing. This commitment to methodological diversity is one factor that helps to distinguish personality psychology from social psychology, a field that often is tied strongly to laboratory experiments to the exclusion of other methods (Robins, Tracy, \& Sherman, 2007). This methodological pluralism also places a burden on personality researchers as it means that they must keep up with changing technologies, research tools, and statistical methods. Thus, the methodological and statistical training of future personality psychologists will be characterized as intense, diverse, and ongoing throughout a research career.

As with methodological pluralism, we also foresee the field maintaining a big tent perspective in terms of its ability and willingness to sustain multiple paradigms and support the search for answers to a wide range of interesting research questions. We predict the kinds of integrative models that identify multiple levels of analysis, such as the one proposed 
by McAdams and Pals (2006), will continue to guide how the field conceptualizes personality. All units of analysis from traits to life stories are an important part of human individuality. Understanding how these elements relate to each other and how they are shaped by biology, culture, developmental experiences, and current life conditions is a daunting task. Addressing all of these different issues is nonetheless essential for the broad science of human individuality envisioned by Allport.

\section{On the Identity of Personality Psychology} In light of its strong foundation and recent methodological and conceptual advances, we are excited for the future of personality psychology. In that spirit, we conclude with a few thoughts about the future of personality psychology as a distinct discipline within psychology. One promising direction is the movement to pull the various strands of personality psychology together into a single entity. Currently, temperament researchers study personality in children, animal behavior researchers study "behavioral syndromes," molecular geneticists explore the genes underlying different behavioral traits, emotion researchers study affective processes that are linked closely to personality, and social psychologists study trait-like constructs yet avoid using the term. Many researchers in these areas of inquiry do not identify themselves as personality researchers despite the fact that they are conducting personality research. This diffusion needs to change, for both substantive reasons (greater scientific understanding will accrue by interconnecting these diverse areas of knowledge) and political reasons (there is power in numbers). Establishing the identity of the field is no doubt an ongoing and never-ending process, but a more unified personality psychology will combat fragmentation and further increase the relevance of the discipline.

Assuming that personality psychology becomes an even more integrated discipline, a natural question then becomes where personality psychologists should be housed in academic departments.

Throughout its history, personality psychology often has been aligned closely with other, often larger and more visible fields, such as clinical psychology and social psychology. Currently, personality psychology generally is viewed as a sibling discipline of social psychology. In some ways, the two areas form a natural alliance, with their collective investigation into the mutual influences of the person and the situation, and the host of substantive topics that are of interest to both areas (achievement, aggression, relationships, self-esteem, well-being, etc.). At times, however, this affiliation may seem uncomfortable, as personality psychologists can feel like a younger and much-neglected sibling (sometimes for good reason and sometimes not). It is possible that a greater number of independent programs in personality psychology will be established at major research universities in the future. This would seem to be a positive step for the discipline.

At the same time, resources may not be sufficient to support a large number of independent personality programs, and we have concerns that there may not be enough jobs for newly minted doctoral graduates. We also believe that personality psychology gains something valuable by being associated with larger and more influential areas of psychology, as long as it can do so without being lost in the shadows. The perspectives of a personality psychologist complement and enhance fields like clinical, developmental, health, and social psychology. To be sure, personality psychology has its own unique intellectual tradition that stands apart from other branches like clinical and social psychology. We hope this heritage is preserved regardless of where personality psychologists are housed in a given department. Nonetheless, we hope for a time in which every psychology department has at least one or two card-carrying personality psychologists in its membership. Indeed, Allport (1937) noted that "to keep the individual in mind is to enrich research in any department of mental science" (p. 565).

Speaking more broadly, we also can imagine the possibility that narrow disciplinary boundaries are less relevant in the future. We have a sense that psychology and other social sciences (if not our very universities) are moving toward more integrative perspectives. For instance, it is not unusual to see economists interested in behavioral genetics and sociologists interested in hormones and specific genetic polymorphisms. Personality psychology is poised to play a significant role in fostering this kind 
of integration as the social sciences embrace multilevel, interdisciplinary approaches that pay increasing attention to the causes and consequence of individual differences. Personality psychology is in such a strong position, in part, because of the keen insights of Allport. Accordingly, we hope his vision for the field is preserved well into the 21 st century.

\section{THE FUTURE OF PERSONALITY PSYCHOLOGY: A NEAR-CONSENSUS}

\section{David C. Funder}

As Donnellan and Robins noted in their contribution, human nature has a common core as well as individual differences. So, too, do the preceding six contributions outlining the expected and desired future of personality psychology, but the common core seems more notable than the differences. In this final section, I try to highlight some of the more important observations and emergent themes, but I will be selective-I promise not to consider all of them.

\section{The Body}

Fraley noted that the perennial concerns of personality psychology include the constraints that biological facts (as well as social structure) place on human development. King highlighted the importance of biology by noting that humans inevitably are situated within bodies. Although embodiment might seem like an obvious fact, she noted, the whole "person-situation" debate was premised on a manifestly false mind-body dualism.

Appreciating the role of the body leads naturally to an emphasis on the biology of personality, as noted also by Donnellan and Robins and, in a different way, by Gosling. Anybody with the Sisyphean task of revising a personality textbook every 3 years is well aware of the explosion and acceleration ${ }^{4}$ of research on the anatomy, physiology, and genetics of personality, along with ever-more-creative and broader use of evolutionary theory to explain the roots of human nature. Gosling pointed out a further biological approach, in which he is a pioneer, of using animal models to explore fundamental elements and processes of personality. The use of animal models is common elsewhere in the life sciences and has a long history in the study of learning-personality psychology is just starting to catch up.

\section{Process}

As Fleeson noted, personality traits often have been treated as "black boxes." We can measure traits and use them to predict and even to understand behavior, but personality psychology generally has not asked many questions about what is going on inside. Opening up these boxes will, as Fraley commented, require attention to within-person patterns of personality and behavior as well as between-person differences. A better understanding of the cognitive (and biological) processes that underlie the effects of personality traits will, as Fleeson, Donnellan, and Roberts observed, lead to new ideas about how to intervene and prevent persistent self-destructive patterns of behavior.

\section{Methodological Innovation}

Almost all of the contributors mentioned the burgeoning methodological advances of personality psychology, and Fraley noted the important implications for graduate training. To a degree probably underappreciated by our colleagues elsewhere in psychology, personality psychologists have a long tradition of methodological rigor in general and statistical sophistication and innovation in particular. For example, as Benet-Martínez noted, multilevel modeling can be used to explore individual differences within cultures simultaneously with group differences between cultures. I will throw in a plug for randomization analyses, which bypasses the necessity for making sometimes-implausible statistical assumptions and provides a robust way to let the data speak for themselves (Sherman $\&$ Funder, 2009).

Personality psychology is at the forefront of technological innovation as well. As Fraley and Gosling noted, methods of mobile data gathering, such as the EAR technique, rapidly are becoming routine and new generations of methods that will

${ }^{4}$ I apologize to readers who do not think explosions can accelerate. 
allow video as well as audio recording are not far behind. Fleeson and Gosling both noted that the Internet opens another wide new window onto human behavior, through the sudden ability to obtain samples of thousands of research participants at little cost, the possibility to examine how people behave in virtual realities, and the use of social media to view directly how people interact with each online. If Facebook is not about human personality, I do not know what is.

\section{Relevance}

Nearly all the contributors evince a concern with maintaining the relevance of personality to the rest of psychology and to the wider world, increasing that relevance, or making the relevance better understood (in particular, see Fraley, King, and Fleeson). As King noted, personality is likely to thrive to the extent that it discovers rather than invents its topics of study. Important issues abound to which personality is directly relevant, but we do not always focus our efforts on them. As funding sources, notably the National Institutes of Health, increasingly insist on applied or "translational" research, we will be forced to do this to survive.

Fleeson noted that the likely dramatic effects of the new Diagnostic and Statistical Manual of Mental Disorders on clinical psychology opens a golden opportunity as personality disorders come to be seen-correctly-as extremes of the normal range that personality psychologists have studied for decades. Thus, personality psychology not only has an opportunity to contribute to clinical psychology but the reverse is true as well. As Fleeson pointed out, "clinical disorders are the psychological equivalents of centrifuges-they concentrate many of the interesting events, behaviors and emotions of normal personality into shorter time periods, allowing more intensive study of the interesting components of personality" (p.10).

\section{Integration}

A final common theme concerns the relations between personality and the rest of psychology. As I mentioned at the outset of this chapter, personality integrates all of the other subfields, but this integrative capacity is not always recognized or appreciated.
Fraley blamed this, in part, on the insularity of personality psychologists who fail to recognize the relevance of work in other fields to their own, butalong with Donnellan and Robins-I think it might mostly be the other way around. Developmental psychologists study temperament, biological psychologists study trait genetics, and social psychologists study chronic emotional or perceptual sensitivities, schemas, implicit theories, and most of all "the self," typically without self-identifying as personality psychologists or even realizing that their work is directly relevant to personality.

Part of our job, as psychologists unafraid to be identified with the field, is to teach these colleagues about what they are doing and, as tactfully as possible, help them to do it better. For example, our social psychological colleagues might benefit, as they develop ad hoc measures of individual differences, from a teensy bit of attention to issues of scale construction, reliability, and construct validation that they think they can bypass as long as they do not call their variable a "trait." They might even find it illuminating to compare their measures to the Big Five or other established personality measuresbut we will have to be very gentle in the way we suggest this.

A true dilemma for personality psychology, and one I have not fully resolved for myself, is the degree to which personality psychology will or should survive as an independent discipline. On the one hand, isolation makes us weak and the field seem small, when the reach of our research is probably larger than that of any area of psychology. On the other hand, to integrate with other fields-social psychology being the usual candidate, but clinical is another possibility-could cause the field to lose not only its identity but also its theoretical history and long tradition of methodological rigor, particularly in the area of measurement. For now, the best answer I see is suggested by Benet-Martínez, whose research shows that individuals socialized in more than one culture can find their multiculturalism to be a source of stress or of strength. If we can become the latter kind of multicultural individuals_-simultaneously maintaining an identification with other areas of psychology and personality psychology - that is likely to be in the best interests of each of us as 
individuals as well as of the important area of research to which we are proud to contribute.

\section{References}

Allport, G. W. (1937). Personality: A psychological interpretation. New York, NY: Henry Holt and Company.

Allport, G. W. (1946). Personalistic psychology as science: A reply. Psychological Review, 53, 132-135. doi:10.1037/h0058477

Allport, G. W. (1961). Pattern and growth in personality. New York, NY: Holt, Rinehart, \& Winston.

Almlund, M., Duckworth, A. L., Heckman, J. J., \& Kautz, T. D. (2011). Personality Psychology and Economics. Working paper, National Bureau of Economic Research.

Amiot, C. E., de la Sablonniere, R., Terry, D. J., \& Smith, J. R. (2007). Integration of social identities in the self: Toward a cognitive-developmental model. Personality and Social Psychology Review, 11, 364-388. doi:10.1177/1088868307304091

Ashton, M. C., \& Lee, K. (2007). Empirical, theoretical, and practical advantages of the HEXACO model of personality structure. Personality and Social Psychology Review, 11, 150-166. doi:10.1177/1088868306294907

Barbaranelli, C., Caprara, G. V., Vecchione, M., \& Fraley, R. C. (2007). Voters' personality traits in presidential elections. Personality and Individual Differences, 42, 1199-1208. doi:10.1016/j.paid.2006.09.029

Baumeister, R. F., Vohs, K. D., \& Funder, D. C. (2007). Psychology as the science of self-reports and finger movements: Whatever happened to actual behavior? Perspectives on Psychological Science, 2, 396-403. doi:10.1111/j.1745-6916.2007.00051.x

Benet-Martínez, V. (2007). Cross-cultural personality research: Conceptual and methodological issues. In R. W. Robins, R. C. Fraley, \& R. Krueger (Eds.), Handbook of research methods in personality psychology (pp. 170-190). New York, NY: Guilford Press.

Benet-Martínez, V. (2012). Multiculturalism: Cultural, personality, and social processes. In K. Deaux \& $\mathrm{M}$. Snyder (Eds.), Handbook of personality and social psychology (pp. 623-648). New York, NY: Oxford University Press.

Benet-Martínez, V., \& Haritatos, J. (2005). Bicultural identity integration (BII): Components and psychosocial antecedents. Journal of Personality, 73, 1015-1050. doi:10.1111/j.1467-6494.2005.00337.x

Benet-Martínez, V., \& John, O. (1998). Los Cinco Grandes across cultures and ethnic groups: Multitrait multimethod analyses of the Big Five in Spanish and English. Journal of Personality and Social Psychology, 75, 729-750. doi:10.1037/0022-3514.75.3.729
Benet-Martínez, V., Lee, F., \& Leu, J. (2006). Biculturalism and cognitive complexity: Expertise in cultural representations. Journal of Cross-Cultural Psychology, 37, 386-407. doi:10.1177/0022022106288476

Benet-Martínez, V., \& Oishi, S. (2008). Culture and personality. In O. P. John, R. W. Robins, \& L. A. Pervin (Eds.), Handbook of personality: Theory and research (pp. 785-806). New York, NY: Guilford Press.

Buhrmester, M., Kwang, T., \& Gosling, S. D. (2011). Amazon's Mechanical Turk: A new source of inexpensive, yet high-quality, data? Perspectives on Psychological Science, 6, 3-5. doi:10.1177/1745691610393980

Canli, T. (2008). Toward a "molecular psychology" of personality. In O. P. John, R. W. Robins, \& L. A. Pervin (Eds.), Handbook of personality: Theory and research (3rd ed., pp. 311-327). New York, NY: Guilford Press.

Caprara, G. V., Vecchione, M., Barbaranelli, C., \& Fraley, R. C. (2007). When likeness goes with liking: The case of political preference. Political Psychology, 28, 609-632. doi:10.1111/j.1467-9221.2007.00592.x

Carlson, R. (1971). Where is the person in personality research? Psychological Bulletin, 75, 203-219. doi:10.1037/h0030469

Caspi, A., Roberts, B. W., \& Shiner, R. (2005). Personality development. Annual Review of Psychology, 56, 453484. doi:10.1146/annurev.psych.55.090902.141913

Cervone, D., \& Mischel, W. (2002). Personality science. In D. Cervone $\&$ W. Mischel (Eds.), Advances in personality science (pp. 1-26). New York, NY: Guilford Press.

Chen, S. X., Benet-Martínez, V., \& Bond, M. H. (2008). Bicultural identity, bilingualism, and psychological adjustment in multicultural societies: Immigrationbased and globalization-based acculturation. Journal of Personality, 76, 803-838. doi:10.1111/j.14676494.2008.00505.x

Chiu, C.-Y., \& Hong, Y.-Y. (2007). Cultural processes: Basic principles. In E. T. Higgins \& A. E. Kruglanski (Eds.), Social psychology: Handbook of basic principles (pp. 785-804). New York, NY: Guilford Press.

Church, A. T. (2010). Current perspectives in the study of personality across cultures. Perspectives on Psychological Science, 5, 441-449. doi:10.1177/1745691610375559

Cohen, D. (1996). Law, social policy, and violence. Journal of Personality and Social Psychology, 70, 961-978. doi:10.1037/0022-3514.70.5.961

Cohn, M. A., Mehl, M. R., \& Pennebaker, J. W. (2004). Linguistic indicators of psychological change after September 11, 2001. Psychological Science, 15, 687-693. doi:10.1111/j.0956-7976.2004.00741.x 
de Moor, M. H. M., Costa, P. T., Jr., Terracciano, A., Kreuger, R. F., de Geus, E. J. C., Toshiko, T., . . . Boomsma, D. I. (2012). Meta-analysis of genomewide association studies for personality. Molecular Psychiatry, 17, 337-349. doi:10.1038/mp.2010.128

DeYoung, C. G., Hirsh, J. B., Shane, M. S., Papademtris, X., Rajeevan, N., \& Gray, J. R. (2010). Testing predictions from personality neuroscience: Brain structure and the Big Five. Psychological Science, 21, 820-828. doi:10.1177/0956797610370159

Duckworth, A. L., Quinn, P. D., Lynam, D. R., Loeber, R., \& Stouthamer-Loeber, M. (2011). Role of test motivation in intelligence testing. Proceedings of the National Academy of Sciences, USA, 108, 7716-7720. doi:10.1073/pnas.1018601108

Dyrenforth, P. S., Kashy, D. A., Donnellan, M. B., \& Lucas, R. E. (2010). Predicting relationship and life satisfaction in nationally representative samples from three countries: The relative importance of actor, partner, and couple similarity effects for personality traits. Journal of Personality and Social Psychology, 99, 690-702. doi:10.1037/a0020385

Eastwick, P. W. (2009). Beyond the Pleistocene: Using phylogeny and constraint to inform the evolutionary psychology of human mating. Psychological Bulletin, 135, 794-821. doi:10.1037/a0016845

Eid, M., \& Diener, E. (2001). Norms for experiencing emotions in different cultures: Inter- and intranational differences. Journal of Personality and Social Psychology, 81, 869-885. doi:10.1037/ 0022-3514.81.5.869

Epstein, S. (1979). The stability of behavior: I. On predicting most of the people much of the time. Journal of Personality and Social Psychology, 37, 1097-1126. doi:10.1037/0022-3514.37.7.1097

Fleeson, W. (2001). Towards a structure- and processintegrated view of personality: Traits as density distributions of states. Journal of Personality and Social Psychology, 80, 1011-1027. doi:10.1037/ 0022-3514.80.6.1011

Fleeson, W. (2012). Perspectives on the person: Rapid growth and opportunities for integration. In K. Deaux \& M. Snyder (Eds.), The Oxford handbook of personality and social psychology (pp. 33-63). New York, NY: Oxford University Press.

Fleeson, W., \& Gallagher, P. (2009). The implications of Big-Five standing for the distribution of trait manifestation in behavior: Fifteen experience-sampling studies and a meta-analysis. Journal of Personality and Social Psychology, 97, 1097-1114. doi:10.1037/ a0016786

Fleeson, W., \& Noftle, E. E. (2009). In favor of the synthetic resolution to the person-situation debate. Journal of Research in Personality, 43, 150-154. doi:10.1016/j.jrp.2009.02.008
Foster, E. M. (2010). Causal inference and developmental psychology. Developmental Psychology, 46, 1454-1480. doi:10.1037/a0020204

Freeman, D., Garety, P. A., Bebbington, P., Slater, M., Kuipers, E., Fowler, D., . . D Dunn, G. (2005). The psychology of persecutory ideation II: A virtual reality experimental study. Journal of Nervous and Mental Disease, 193, 309-315. doi:10.1097/01. nmd.0000161686.53245.70

Funder, D. C. (2001). Personality. Annual Review of Psychology, 52, 197-221. doi:10.1146/annurev. psych.52.1.197

Funder, D. C. (2013). The personality puzzle (6th ed.). New York, NY: W. W. Norton.

Funder, D. C., \& Colvin, C. R. (1991). Explorations in behavioral consistency: Properties of persons, situations, and behaviors. Journal of Personality and Social Psychology, 60, 773-794. doi:10.1037/ 0022-3514.60.5.773

Funder, D. C., \& Fast, L. A. (2010). Personality in social psychology. In D. Gilbert \& S. Fiske (Eds.), Handbook of social psychology (5th ed., pp. 668-697). New York, NY: Wiley.

Funder, D. C., \& Ozer, D. J. (1983). Behavior as a function of the situation. Journal of Personality and Social Psychology, 44, 107-112. doi:10.1037/ 0022-3514.44.1.107

Furr, R. M. (2009). Personality psychology as a truly behavioral science. European Journal of Personality, 23, 369-401. doi:10.1002/per.724

Gallego, A., \& Oberski, D. (2012). Personality and political participation: The mediation hypothesis. Political Behavior, 34, 425-451. doi:10.1007/s11109-011-9168-7

Gosling, S. D. (2001). From mice to men: What can we learn about personality from animal research? Psychological Bulletin, 127, 45-86. doi:10.1037/ 0033-2909.127.1.45

Gosling, S. D. (2008). Personality in non-human animals. Social and Personality Psychology Compass, 2, 985-1001. doi:10.1111/j.1751-9004.2008.00087.x

Gosling, S. D., \& Graybeal, A. (2007). Tree thinking: A new paradigm for integrating comparative data in psychology. Journal of General Psychology, 134, 259-277. doi:10.3200/GENP.134.2.259-278

Gosling, S. D., Ko, S. J., Mannarelli, T., \& Morris, M. E. (2002). A room with a cue: Judgments of personality based on offices and bedrooms. Journal of Personality and Social Psychology, 82, 379-398. doi:10.1037/0022-3514.82.3.379

Gosling, S. D., Sandy, C. J., John, O. P., \& Potter, J. (2010). Wired but not WEIRD: The promise of the Internet in reaching more diverse samples. Behavioral and Brain Sciences, 33, 94-95. doi:10.1017/S0140525X10000300 
Gosling, S. D., Vazire, S., Srivastava, S., \& John, O. P. (2004). Should we trust web-based studies? A comparative analysis of six preconceptions about Internet questionnaires. American Psychologist, 59, 93-104. doi:10.1037/0003-066X.59.2.93

Heckman, J. J. (2008). Econometric causality. International Statistical Review, 76, 1-27. doi:10.1111/j.17515823.2007.00024.x

Henrich, J., Heine, S. J., \& Norenzayan, A. (2010). The weirdest people in the world? Behavioral and Brain Sciences, 33, 61-83, 111-135. doi:10.1017/ S0140525X0999152X

Hong, Y. Y., Morris, M., Chiu, C. Y., \& Benet-Martínez, V. (2000). Multicultural minds: A dynamic constructivist approach to culture and cognition. American Psychologist, 55, 709-720. doi:10.1037/0003066X.55.7.709

Jackson, J. J., Hill, P. L., Payne, B. R., Roberts, B. W., $\&$ Stine-Morrow, E. A. L. (2012). Can an old dog learn (and want to experience) new tricks? Cognitive training increases openness to experience in older adults. Psychology and Aging, 27, 286-292. doi:10.1037/a0025918

Johnson, J. A. (2010). Web-based self-report personality scales. In S. D. Gosling \& J. A. Johnson (Eds.), Advanced methods for conducting online behavioral research (pp. 149-166). Washington, DC: American Psychological Association. doi:10.1037/12076-010

Johnson, J. A., \& Gosling, S. D. (2010). How to use this book. In S. D. Gosling \& J. A. Johnson (Eds.), Advanced methods for conducting online behavioral research (pp. 3-7). Washington, DC: American Psychological Association. doi:10.1037/12076-001

Jones, E. E. (1990). Interpersonal perception. New York, NY: W. H. Freeman.

Jost, J. T., Glaser, J., Kruglanski, A. W., \& Sulloway, F. (2003). Political conservatism as motivated social cognition. Psychological Bulletin, 129, 339-375. doi:10.1037/0033-2909.129.3.339

Judge, T. A., Heller, D., \& Klinger, R. (2008). The dispositional sources of job satisfaction: A comparative test. Applied Psychology: An International Review, 57, 361-372. doi:10.1111/j.1464-0597.2007.00318.x

Kenny, D. A. (1975). Cross-lagged panel correlation: A test for spuriousness. Psychological Bulletin, 82, 887-903. doi:10.1037/0033-2909.82.6.887

Kenrick, D. T., \& Funder, D. C. (1988). Profiting from controversy: Lessons from the personsituation debate. American Psychologist, 43, 23-34. doi:10.1037/0003-066X.43.1.23

Larsen, R. J., \& Buss, D. M. (2009). Personality psychology: Domains of knowledge about human nature (4th ed.). New York, NY: McGraw-Hill.

Leung, A. K.-Y., Maddux, W. W., Galinsky, A. D., $\&$ Chiu, C. Y. (2008). Multicultural experience enhances creativity: The when and how. American Psychologist, 63, 169-181. doi:10.1037/0003066X.63.3.169

Leung, K., \& Bond, M. H. (1989). On the empirical identification of dimensions for crosscultural comparisons. Journal of Cross-Cultural Psychology, 20, 133-151. doi:10.1177/0022022189202002

Lucas, R. E., \& Diener, E. (2008). Can we learn about national differences in happiness from individual responses? A multilevel approach. Multilevel analysis of individuals and cultures. In F. J. R. van de Vijver, D. A. van Hemert, \& Y. H. Poortinga (Eds.), Multilevel analysis of individuals and cultures (pp. 223-248). New York, NY: Erlbaum.

Lucas, R. E., \& Donnellan, M. B. (2009). If the person-situation debate is really over, why does it still generate so much negative affect? Journal of Research in Personality, 43, 146-149. doi:10.1016/ j.jrp.2009.02.009

Markus, H. R., \& Kitayama, S. (1998). The cultural psychology of personality. Journal of CrossCultural Psychology, 29, 63-87. doi:10.1177/ 0022022198291004

McAdams, D. P., \& Pals, J. L. (2006). A new Big Five: Fundamental principles for an integrative science of personality. American Psychologist, 61, 204-217. doi:10.1037/0003-066X.61.3.204

McCrae, R. R. (2004). Human nature and culture: A trait perspective. Journal of Research in Personality, 38, 3-14. doi:10.1016/j.jrp.2003.09.009

Mehl, M. R., \& Conner, T. S. (Eds.). (2012). Handbook of research methods for studying daily life. New York, NY: Guilford Press.

Mehl, M. R., Pennebaker, J. W., Crow, M. D., Dabbs, J., $\&$ Price, J. H. (2001). The Electronically Activated Recorder (EAR): A device for sampling naturalistic daily activities and conversations. Behavior Research Methods, Instruments, and Computers, 33, 517-523. doi:10.3758/BF03195410

Meyer, G. J., Finn, S. E., Eyde, L. D., Kay, G. G., Moreland, K. L., Dies, R. R., . . Reed, G. M. (2001). Psychological testing and psychological assessment: A review of evidence and issues. American Psychologist, 56, 128-165. doi:10.1037/0003-066X.56.2.128

Mikulincer, M., \& Shaver, P. R. (2007). Attachment in adulthood: Structure, dynamics, and change. New York, NY: Guilford Press.

Mischel, W. (1968). Personality and assessment. New York, NY: Wiley.

Mischel, W. (1973). Towards a cognitive social learning reconceptualization of personality. Psychological Review, 80, 252-283. doi:10.1037/h0035002

Mischel, W., \& Shoda, Y. (1998). Reconciling processing dynamics and personality dispositions. Annual 
Review of Psychology, 49, 229-258. doi:10.1146/ annurev.psych.49.1.229

Moffitt, T. E., Arseneault, L., Belsky, D., Dickson, N., Hancox, R. J., Harrington, H., . . . Caspi, A. (2011). A gradient of childhood self-control predicts health, wealth, and public safety. Proceedings of the National Academy of Sciences, USA, 108, 2693-2698. doi:10.1073/pnas.1010076108

Nezlek, J. B. (2007). Multilevel modeling in research on personality. In R. Robins, R. C. Fraley, \& R. Krueger (Eds.), Handbook of research methods in personality psychology (pp. 502-523). New York, NY: Guilford Press.

Norenzayan, A., \& Heine, S. J. (2005). Psychological universals: What are they and how can we know? Psychological Bulletin, 131, 763-784. doi:10.1037/0033-2909.131.5.763

Oishi, S. (2004). Personality in culture: A neo-Allportian view. Journal of Research in Personality, 38, 68-74. doi:10.1016/j.jrp.2003.09.012

Ozer, D. J., \& Benet-Martinez, V. (2006). Personality and the prediction of consequential outcomes. Annual Review of Psychology, 57, 401-421. doi:10.1146/ annurev.psych.57.102904.190127

Pinker, S. (2011). The better angels of our nature: Why violence has declined. New York, NY: Viking Press.

Ramírez-Esparza, N., Gosling, S., Benet-Martínez, V., Potter, J., \& Pennebaker, J. (2006). Do bilinguals have two personalities? A special case of cultural frame-switching. Journal of Research in Personality, 40, 99-120. doi:10.1016/j.jrp.2004.09.001

Reeskens, T., \& Wright, M. (2011). Subjective wellbeing and national satisfaction: Taking seriously the "Proud of what?" question. Psychological Science, 22, 1460-1462. doi:10.1177/0956797611419673

Reis, H. T., \& Gosling, S. D. (2010). Social psychological methods outside the laboratory. In S. T. Fiske, D. T. Gilbert, \& G. Lindzey (Eds.), Handbook of social psychology (5th ed., Vol. 1, pp. 82-114). New York, NY: Wiley.

Rentfrow, P. J., \& Gosling, S. D. (2003). The do re mi's of everyday life: The structure and personality correlates of music preferences. Journal of Personality and Social Psychology, 84, 1236-1256. doi:10.1037/ 0022-3514.84.6.1236

Roberts, B. W. (2009). Back to the future: Personality and Assessment and personality development. Journal of Research in Personality, 43, 137-145. doi:10.1016/ j.jrp.2008.12.015

Roberts, B. W., Donnellan, M. B., \& Hill, P. L. (in press). Personality trait development in adulthood: Findings and implications. In I. B. Weiner (Editor-in-Chief) \& H. Tennen (Vol. Ed.), Handbook of psychology: Vol. 5. Personality and social psychology. New York, NY: Wiley.
Roberts, B. W., Kuncel, N. R., Shiner, R., Caspi, A., \& Goldberg, L. R. (2007). The power of personality: The comparative validity of personality traits, socioeconomic status, and cognitive ability for predicting important life outcomes. Perspectives on Psychological Science, 2, 313-345. doi:10.1111/ j.1745-6916.2007.00047.x

Roberts, B. W., Walton, K., \& Viechtbauer, W. (2006). Personality changes in adulthood: Reply to Costa $\&$ McCrae (2006). Psychological Bulletin, 132, 29-32. doi:10.1037/0033-2909.132.1.29

Roberts, B. W., \& Wood, D. (2006). Personality development in the context of the neo-socioanalytic model of personality. Handbook of personality development (pp. 11-39). Mahwah, NJ: Erlbaum.

Robins, R. W., Caspi, A., \& Moffitt, T. E. (2000). Two personalities, one relationship: Both partners' personality traits shape the quality of their relationship. Journal of Personality and Social Psychology, 79, 251259. doi:10.1037/0022-3514.79.2.251

Robins, R. W., Tracy, J. L., \& Sherman, J. W. (2007). What kinds of methods do personality psychologists use? A survey of editors and editorial board members. In R. W. Robins, R. C. Fraley, \& R. F. Krueger (Eds.), Handbook of research methods in personality psychology (pp. 673-678). New York, NY: Guilford Press.

Rohner, R. (1984). Toward a conception of culture for cross-cultural psychology. Journal of Cross-Cultural Psychology, 15, 111-138. doi:10.1177/0022002184015002002

Rosenbaum, P. R., \& Rubin, D. B. (1983). The central role of the propensity score in observational studies for causal effects. Biometrika, 70, 41-55. doi:10.1093/ biomet/70.1.41

Rozin, P. (2001). Social psychology and science: Some lessons from Solomon Asch. Personality and Social Psychology Review, 5, 2-14. doi:10.1207/ S15327957PSPR0501_1

Rozin, P. (2003). Five potential principles for understanding cultural differences in relation to individual differences. Journal of Research in Personality, 37, 273-283. doi:10.1016/S0092-6566(02)00566-4

Rozin, P. (2006). Domain denigration and process preference in academic psychology. Perspectives on Psychological Science, 1, 365-376. doi:10.1111/ j.1745-6916.2006.00021.x

Rozin, P. (2009). What kind of empirical research should we publish, fund, and reward: A different perspective. Perspectives on Psychological Science, 4, 435439. doi:10.1111/j.1745-6924.2009.01151.x

Ryder, A. G., Alden, L., \& Paulhus, D. (2000). Is acculturation unidimensional or bidimensional? A headto-head comparison in the prediction of personality, 
self-identity, and adjustment. Journal of Personality and Social Psychology, 79, 49-65. doi:10.1037/ 0022-3514.79.1.49

Schimmack, U., Radhakrishnan, P., Oishi, S., Dzokoto, V., $\&$ Ahadi, S. (2002). Culture, personality, and subjective well-being: Integrating process models of life satisfaction. Journal of Personality and Social Psychology, 82, 582-593. doi:10.1037/0022-3514.82.4.582

Sherman, R. A., \& Funder, D. C. (2009). Evaluating correlations in studies of personality and behavior: Beyond the number of significant findings to be expected by chance. Journal of Research in Personality, 43, 1053-1063. doi:10.1016/ j.jrp.2009.05.010

Simmons, J. P., Nelson, L. D., \& Simonsohn, U. (2011). False-positive psychology: Undisclosed flexibility in data collection and analysis allows presenting anything as significant. Psychological Science, 22, 1359-1366. doi:10.1177/0956797611417632

Sinn, D. L., Gosling, S. D., \& Hilliard, S. J. (2010). Personality and performance in military working dogs: Reliability and predictive validity of behavioral tests. Applied Animal Behaviour Science, 127, 51-65. doi:10.1016/j.applanim.2010.08.007

Soto, C. J., John, O. P., Gosling, S. D., \& Potter, J. (2011). Age differences in personality traits from 10 to 65: Big Five domains and facets in a large cross-sectional sample. Journal of Personality and Social Psychology, 100, 330-348. doi:10.1037/a0021717

Sroufe, L. A. (1989). Relationships, self, and individual adaptation. In A. J. Sameroff \& R. N. Emde (Eds.), Relationship disturbances in early childhood: A developmental approach (pp. 70-94). New York, NY: Basic Books.

Stukeley, W. (1752). A memoir of Isaac Newton. Retrieved from http://www.royalsociety.org/turningthepages

Swann, W. B., Jr., \& Seyle, C. (2005). Personality psychology's comeback and its emerging symbiosis with social psychology. Personality and Social Psychology Bulletin, 31, 155-165. doi:10.1177/0146167204271591

Terracciano, A., Abdel-Khalek, A. M., Ádám, N., Adamovová, L., Ahn, C.-K., Ahn, H. N., . . McCrae, R. R. (2005). National character does not reflect mean personality trait levels in 49 cultures. Science, 310, 96-100. doi:10.1126/science.1117199

Tracy, J. L., Robins, R. W., \& Sherman, J. W. (2009). The practice of psychological science: Searching for Cronbach's two streams in social-personality psychology. Journal of Personality and Social Psychology, 96, 1206-1225. doi:10.1037/a0015173

Triandis, H. C. (1996). The psychological measurement of cultural syndromes. American Psychologist, 51, 407-415. doi:10.1037/0003-066X.51.4.407

Van Der Zee, K. I., Atsma, N., \& Brodbeck, F. C. (2004). The influence of social identity and personality on outcomes of cultural diversity in teams. Journal of Cross-Cultural Psychology, 35, 283-303. doi:10.1177/0022022104264123

van de Vijver, F. J. R., van Hemert, D. A., \& Poortinga, Y. H. (Eds.). (2008). Multilevel analysis of individuals and cultures. New York, NY: Erlbaum.

Vazire, S. (2010). Informant reports. In S. D. Gosling $\& \mathrm{~J}$. A. Johnson (Eds.), Advanced methods for conducting online behavioral research (pp. 167-178). Washington, DC: American Psychological Association. doi:10.1037/12076-011

Vazire, S., \& Gosling, S. D. (2004). E-perceptions: Personality impressions based on personal websites. Journal of Personality and Social Psychology, 87, 123-132. doi:10.1037/0022-3514.87.1.123

Weinstein, T. A. R., Capitanio, J. P., \& Gosling, S. D. (2008). Personality in animals. In O. P. John, R. W. Robins, \& L. A. Pervin (Eds.), Handbook of personality theory and research (pp. 328-348). New York, NY: Guilford Press. 